\title{
O Valor da Diversidade Racial nas Empresas
}

Aaron Myers

\section{Resumo}

Apesar de constituir quase metade da população brasileira, os afro-brasileiros são sub-representados nas empresas, em particular nos altos escalōes. Algumas empresas no Brasil estão desenvolvendo iniciativas em favor da diversidade que visam à inclusão de afrodescendentes, entre outros grupos historicamente discriminados, no mercado de trabalho. Durante cinco meses, o autor desta comunicação investigou e entrevistou representantes desses programas de diversidade no Rio de Janeiro e em São Paulo. Serão apresentados os resultados de sua pesquisa, que analisa as estratégias, justificativas e impacto da promoção da diversidade racial no setor privado.

Palavras-chave: negros, diversidade, recursos humanos, responsabilidade social empresarial, investimento social privado.

\section{Abstract}

While Afro-Brazilians make up nearly half of Brazil's population, they are under-represented in businesses, especially in the upper echelons. Some businesses in Brazil are developing initiatives to promote diversity that seek to increase the representation of Afro-Brazilians among other historically discriminated groups in the private sector. During five months, the author of this report investigated and interviewed representatives of these diversity initiatives in Rio de Janeiro and São Paulo. It analyzes the situation of blacks in the labor market and in businesses, the ethical and economic justifications for diversity initiatives, and the strategies and results of such initiatives.

Keywords: Blacks, diversity, human resources, corporate social responsibility, social private investment. 


\section{Résumé}

La valeur de la diversité raciale dans les entreprises

Même s'ils constituent presque la moitié de la population brésilienne, les afro-descendants sont sous-représentés dans les entreprises, surtout dans les postes de haut niveau. Au Brésil, certaines entreprises sont en train de mettre sur pied des iniciatives en faveur de la diversité et qui favorisent l'inclusion d'afro-descendants, parmi d'autres groupes historiquement discriminés, sur le marché du travail. Pendant cind mois, l'auteur de cet article a fait des enquêtes et a interviewé des représentants de ces progammes de diversité à Rio de Janeiro et à São Paulo. On prsente ici les résultats de cette recherche qui analyse les stratégies, les justifications et l'impact de la promotion de la diversité raciale dans le secteur privé.

Mots-clés: Noirs, diversité, ressources humaines, responsabilité sociale des entreprises, investissement social privé. 


\section{Introdução}

7 urante os anos 90, a globalização, o multiculturalismo, e o movimento pela responsabilidade social empresarial provocaram mudanças sobre como pensarmos e agirmos diante uma sociedade e um mercado cada vez mais diversos. No Brasil, esses desenvolvimentos junto às reivindicações do movimento negro e do movimento sindical colocaram em pauta as questóes de discriminação e diversidade raciais e geraram um diálogo nacional em torno delas. As instituições públicas, privadas e as do terceiro setor começaram a assumir o desafio de diminuir a discriminação racial e ao mesmo tempo procurar maneiras de abraçar a diversidade racial que caracteriza o país. Surgiram ações afirmativas na forma de cotas raciais em algumas universidades e alguns Ministérios, estimulando ainda mais o debate. As empresas não podiam ficar fora da discussão por muito tempo e começaram a tomar medidas em resposta às cobranças da sociedade e/ou em função da disseminação de políticas e práticas de diversidade, oriundas de suas matrizes localizadas em países estrangeiros.

As políticas de diversidade têm por objetivo "a adoção de iniciativas, atividades e medidas que reconheçam e promovam a diferença entre pessoas ou grupos como um valor positivo a ser desenvolvido como instrumento de integração social, em benefício da produtividade da empresa e da democratização das oportunidades de acesso e tratamento no mercado de trabalho" (Alexim, 1999). Esse relatório analisa as atividades das empresas na área de promoção de diversidade com foco na população afro-brasileira. A primeira parte do relatório resume e analisa as estatísticas e a literatura relacionadas com discriminação e diversidade racial no mercado de trabalho e nas empresas. A segunda parte resume e analisa as experiências de treze empresas brasileiras na promoção de diversidade racial. O relatório conclui com uma série de recomendações. Dada a dificuldade que muitas empresas têm em lidar com questôes raciais, o objetivo da pesquisa é destacar a importância da in- 
clusão racial no setor privado e sugerir linhas de ação para as empresas realizarem o valor da diversidade racial.

\section{Revisão da literatura e apresentação dos dados}

Este relatório começa por mostrar a situação dos negros no mercado de trabalho e nas empresas. O grau de exclusão observado nas empresas é uma reflexão da exclusão que acontece no mercado de trabalho. Essas tendências se revelam nas estatísticas do IBGE e nos estudos recentes do DIEESE e do Instituto Ethos. Depois de apresentar os números, responderei a duas explicações oferecidas pelas empresas: 1) há poucos negros porque poucos deles têm uma formação superior; e 2) a discriminação no Brasil é mais econômica e social do que racial.

Números nacionais: Segundo os números do IBGE, o Brasil tem uma população autodeclarada negra de $46 \%$ (dos quais 5,6\% são pretos e $40,4 \%$, pardos), a população economicamente ativa conta com um contingente negro de 43,3\% (Instituto Ethos, dezembro 2003:15). ${ }^{1} \mathrm{O}$ diploma universitário é privilégio de $6,8 \%$ da população com mais de 25 anos; dessa população com mais de 25 anos e nível superior, $82,8 \%$ são brancos, $14,3 \%$ são negros (12,2\% pardos, 2,1\% pretos) (Escóssia, 3/12/2003). Os números do IBGE também mostram que o rendimento médio mensal da população negra ocupada é $50 \%$ menor que o salário médio da população branca, mesmo que os negros possuam em média 1,5 anos de estudo menos do que os brancos (Instituto Ethos, 2003:6; Ballan, 2002:37). ${ }^{2}$

Números metropolitanos: Em 1999, o Instituto Sindical Interamericano pela Igualdade Racial (INSPIR) publicou o Mapa da População Negra no Mercado de Trabalho no Brasil, uma pesquisa realizada nas regiōes metropolitanas de São Paulo, Belo Horizonte, Salvador, Porto Alegre, Recife, e Distrito Federal. ${ }^{3}$ A população negra abrange $43,7 \%$ das seis regiões metropolitanas e constitui $41,7 \%$ da população economicamente ativa, havendo diferenciações regionais (INSPIR, 1999:15). O Mapa revela que a remuneração do negro é inferior quando comparada com a do branco que exerce a mesma função. Na maioria das capitais pesquisadas, o rendimento médio do trabalhador branco é mais do que o dobro do do negro e os rendimentos dos homens negros são inferiores aos das mulheres brancas em todas as regiões pesquisadas (INSPIR, 1999:6, folheto bilíngüe). Em todas as capitais pesquisadas, os di- 
ferenciais de rendimentos entre negros e brancos aumentam à medida que aumenta a escolaridade; ou seja, o retorno de educação é menor para os negros (Bento, 1999:123). Por fim, as taxas de desemprego são maiores entre os trabalhadores negros, e na maioria das capitais a duração do desemprego é bem maior do que o tempo gasto pelos brancos (57 semanas versus 50 semanas) (INSPIR, 1999:16, versão popular).

Números nas empresas: O Instituto Ethos lançou, em dezembro de 2003, o relatório Perfil social, racial e de gênero das 500 maiores empresas do Brasil e suas açôes afirmativas. A constatação principal desse relatório é a predominância de homens brancos com alto grau de instrução nos principais cargos executivos (Instituto Ethos, 2003:5). E à medida que vai descendo na hierarquia empresarial (níveis: funcional, chefia, gerência, e executivo), encontra-se um número maior de negros, mas o número de negros nas empresas é longe da sua proporção na população nacional. As estatísticas no relatório revelam essas e outras discrepâncias entre funcionários negros e brancos e fornece informações sobre as ações das empresas voltadas para a promoção de diversidade. Segue abaixo um resumo desses dados:

Olhando para dentro das empresas, o relatório do Ethos revela que o retorno de educação é menor para os negros e que estes enfrentam mais barreiras para promoção. Para cada ano de estudo a mais, os brancos têm sua renda elevada em 1,25 salário mínimo, enquanto para os negros essa elevação é de 0,53 salário mínimo (ibidem:6). E enquanto a maioria dos negros do quadro executivo $(53,8 \%)$ têm mais de quinze anos de empresa, só $37,4 \%$ dos executivos brancos e $29,7 \%$ dos amarelos estão nessa mesma condição. Isso significa que os poucos negros a atingir o topo demoraram mais tempo para consegui-lo que os executivos de outras raças ( $i b i$ dem:18).

O Instituto Ethos também solicitou que o presidente desse sua opinião sobre a situação dos negros em cada nível hierárquico da empresa. Em 74\% das empresas não há negros no quadro executivo (primeiro escalão) e $4 \%$ não têm essa informação. É também alto o índice de empresários que declaram não haver negros em nível de gerência ( $42 \%$, segundo escalão), e 1\% deles admitiram que não há negros nem mesmo no quadro funcional (ibidem:22). Chama a atenção a situação da mulher negra, que constitui apenas $0,1 \%$ e $1,0 \%$ dos quadros executivo e de gerência, respectivamente (ibidem:14). 
Em relação às iniciativas das empresas em favor da diversidade, $40 \%$ das que responderam dizem promover açôes desse tipo. Dentre as iniciativas, no entanto, poucas organizações têm políticas claras de promoção de diversidade étnica ou de gênero (ibidem:7). É significativo o apoio a projetos na comunidade que visem melhorar a oferta de profissionais qualificados provenientes de grupos usualmente discriminados no mercado de trabalho (não exclusivamente negros), citado por $24 \%$ das empresas. Por outro lado, apenas $1 \%$ das empresas dizem manter programas para melhorar a capacitação profissional de negros (ibidem:23). ${ }^{6}$

Interpretação dos Dados: Diante desse quadro preocupante de informações, as empresas costumam dizer que não existem negros qualificados ou que poucos negros têm uma formação acadêmica e técnica tão competitiva como a dos brancos (Vassallo, 6/9/2000: 164). Por exemplo, "É objetivo da empresa contratar pessoas negras, mas essas pessoas têm que ter especialização em área específica e a empresa encontra dificuldades nesse recrutamento" (Bento, 2002:58). Por isso, muitas das iniciativas de diversidade racial das empresas estão voltadas para a educação, como veremos mais tarde. Outro discurso comum para explicar a sub-representação de pretos e pardos nas empresas em todos os níveis é que, "No Brasil, as barreiras para contratação não são raciais; são sociais e econômicas" (Vassallo, 27/9/1995:75). ${ }^{8}$

Penso que a falta relativa de escolaridade e de preparo profissional dos negros não é uma explicação adequada para o grau de exclusão registrado pelas estatísticas acima. Reinaldo Bulgarelli, um consultor e especialista na área de diversidade, observa que "Não são apenas os negros e pessoas com deficiência que têm pouca escolaridade, mas a população brasileira em geral. A discriminação vivida por estes dois segmentos agrava a situação, mas não pode ser usada como desculpa para a não existência de pessoas qualificadas para o trabalho. Há barreiras internas no mercado de trabalho, até mesmo nas grandes empresas, nacionais ou multinacionais (que teriam acesso a melhores práticas e boas tecnologias) que precisam ser consideradas também" (Bulgarelli, 24/1/2004, e-mail). Essas barreiras existem não somente na hora da contratação dos negros, mas também na hora de sua promoção. Por exemplo, no relatório do Ethos entre os diretores com pós-graduação ou mestrado, o grupo racial que mais se destaca são os pardos: $44,7 \%$ deles estão nesse grau de escolaridade. Seguem-se os amarelos, com $40,5 \%$, os brancos, com $31,9 \%$, e os pretos, com 21,5\% (Instituto Ethos, 2003:19). O fato de que os negros levam mais tempo para alcançar 
os altos escalóes, mesmo com mais escolaridade que os brancos, sugere que os negros ainda enfrentam barreiras na sua trajetória dentro da empresa.

Ao mesmo tempo, o ponto de vista de que as barreiras enfrentadas pelos negros no mercado de trabalho podem ser explicadas por condiçôes sociais e econômicas é incompleto. Os números do IBGE, INSPIR, e do Instituto Ethos demonstram uma situação de desigualdade para os trabalhadores negros (salários mais baixos, apesar dos mesmos níveis de escolaridade, mais tempo para subir na hierarquia empresarial, apesar de jornadas mais longas e mais anos trabalhando na empresa etc.) e que a discriminação racial interfere em todos os espaços do mercado de trabalho brasileiro e em todos os níveis das empresas (INSPIR, 1999:117). Combate à discriminação e a redução da desigualdade são duas das justificativas citadas pelas empresas por lançarem iniciativas de diversidade. Essas justificativas são analisadas na próxima seção.

\section{Proposição}

As empresas oferecem uma variedade de razões para a adoção de políticas e práticas da promoção de diversidade. A justificativas podem ser divididas em duas categorias: ética e vantagem competitiva. Ou seja, há uma possibilidade de se pensar na promoção de diversidade a serviço de interesses econômicos e sociais (Bellan, 2002:17). Essas duas dimensões — uma baseada nos valores da cidadania e outra na estratégia empresarial — são um reflexo do fato de que as empresas são tanto instituições econômicas como instituições sociais que têm um impacto profundo nas comunidades onde estão inseridas. $\mathrm{O}$ ambiente de trabalho, com seus projetos, suas relações, suas políticas de contratação, oferece uma oportunidade única para tratar de diversidade e inclusão; as inúmeras vantagens e sinergias que um ambiente diversificado trazem para o desempenho da empresa e da sociedade são praticamente inexploradas (Carneiro, 2002:2).

\section{Ética}

Por um lado, a promoção da diversidade faz parte de responsabilidade social empresarial. O tema da diversidade, apesar de presente no meio educacional desde a década de 80 , foi incorporado pelo movimento de responsabilidade social empresarial (RSE) 
durante os anos 90 (Bulgarelli, julho 2002:6). Segundo o Instituto Ethos, responsabilidade social empresarial é uma forma de conduzir os negócios da empresa de tal maneira que a torna parceira e co-responsável pelo desenvolvimento social.' A responsabilidade social visa a uma sociedade mais próspera e justa e envolve ações das empresas contra a pobreza e a desigualdade na própria realização dos negócios (Bulgarelli, julho 2002:7). Ética é a base da responsabilidade social e se expressa por meio dos princípios e valores adotados pela organização.

Um dos valores de muitas empresas é o respeito às pessoas. A promoção da diversidade estimula as pessoas a demonstrarem esse valor. A valorização da diversidade é o respeito às diferenças, o exercício da tolerância, do diálogo, das construções coletivas, de relaçôes de parceria e de complementaridade que têm como base a ética e a valorização, a proteção, o cuidado com a vida e a responsabilidade sobre ela e tudo que diz respeito ao bem comum (Bulgarelli, 17/12/2003:slide 10). A promoção da diversidade concretiza esses valores de cidadania abraçados pelas empresas socialmente responsáveis.

Um dos ditados de responsabilidade social empresarial é que não se pode ter uma ilha de prosperidade num mar de miséria. Essa crença motiva as açóes sociais das empresas em parceria com organizações da sociedade civil nas áreas de educação, saúde, e meio ambiente, por exemplo. Do ponto de vista das empresas que exercem responsabilidade social, tais intervençôes ou investimento em iniciativas sociais (chamado investimento social privado) que melhora as pessoas e protege o meio ambiente garante a sustentabilidade da sociedade e ao mesmo tempo da empresa.

Implícita nos programas de diversidade e na responsabilidade social em geral é a idéia de redistribuição de oportunidades/renda. O Brasil não é um país pobre, mas um país profundamente injusto, ou seja, não se trata de limitação de recursos, mas de sua distribuição, pois a desigualdade de renda não muda no Brasil há pelos menos trinta anos (Ministério de Trabalho e Emprego, 2003:33). Os brancos são 88\% do seleto grupo dos 1\% mais ricos do país, enquanto os negros são 68\% do mais pobres (Loyola, 26/6/2003). Segundo o Professor Hélio Santos, "O país tem uma perda colossal em termos estratégicos por não aproveitar em todos os níveis a mão-de-obra das mulheres e negros - 50,5\% e 45\%, respectivamente, da população brasileira. Pode-se afirmar que as empresas ao discriminarem esses dois segmentos estão operando na contramão do desenvolvimento sustentável do país" (Santos, 
18/12/2003). Num país com sérios problemas raciais, não é possível ao movimento de responsabilidade social empresarial ignorar o papel das empresas no combate aos prejuízos que a discriminação tem causado a todos, principalmente às mulheres negras (Bulgarelli, julho 2002:7). Para construir um país mais justo e mais sustentável, faz-se necessário combater a discriminação racial que gerou e sustenta muito das desigualdades existentes. ${ }^{11}$

É importante anotar que a promoção da diversidade e o combate à discriminação constituem dois lados da mesma moeda. São estratégias complementares. A primeira trata do que quer construir e o segundo trata do que precisa desmontar. Tem que ter os dois para garantir maior eqüidade nas empresas. Os sindicatos têm contribuído muito ao inserir a questão de não-discriminação na agenda empresarial, mas o assunto é pouco discutido nas empresas (Bulgarelli, 17/12/2003). Existe uma condenação formal da discriminação nas empresas, mas nem sempre processos e ferramentas para reduzir a discriminação. É relativamente mais fácil mobilizar os funcionários pela proposta de promover a diversidade porque aborda a realidade de exclusão de uma maneira positiva. A promoção da diversidade não fala daquilo que queremos rejeitar, mas daquilo que queremos promover, estimulando discussões e práticas com base em valores éticos (ibidem). No entanto, a professora Maria Aparecida Bento, do CEERT, diz que "É importante destacar aqui que o termo diversidade não raro é utilizado pelas instituições para relativizar e evitar o enfrentamento da discriminação racial” (Bento, 1999:131; 2000:29).

\section{Vantagem Competitiva}

Pelo lado econômico, a promoção da diversidade apresenta-se como uma vantagem competitiva, como uma estratégia empresarial para garantir a permanência e competitividade da empresa no mercado. Além dos benefícios do ponto de vista ético, programas de diversidade trazem uma série de benefícios econômicos: desempenho financeiro fortalecido; rotatividade de mão-de-obra reduzida; maior produtividade; aumento de satisfação dos empregos nas atividades profissionais; menor vulnerabilidade das empresas face às leis trabalhistas; valorização da imagem empresarial junto aos consumidores e opinião pública em geral; reconhecimento adequado do desempenho e do potencial dos trabalhadores (Bellan, 2002:17). ${ }^{12}$ Adaptação ao mercado e inovação/criativida- 
de são as justificativas econômicas mais relevantes à promoção de diversidade.

Adaptação aos Mercados/Clientes: Diversidade representa uma exigência do mercado atual (Bulgarelli, janeiro 2002:1). A globalização tem aumentado o volume do comércio internacional, o número de fusões e aquisições de empresas entre países, e tem provocado mudanças demográficas e culturais na sociedade. Por isso, é preciso conhecer e adaptar-se aos mercados nacionais e internacionais que estão ficando cada vez mais diversos. "Em um mercado crescentemente diverso, empresas devem estar preparadas para fazer negócios com consumidores, competidores, e parceiros que também estão crescentemente diversos" (Ministério do Trabalho e Emprego, 2003:18). O motor da diversidade é a busca cada vez maior de competências e conhecimento do mercado para manter a competitividade (Vassallo, 6/9/2000:154).

Uma equipe diversificada permite que a empresa aumente seu mercado consumidor. Por ter dentro da empresa pessoas diferentes que entendem os gostos e preferências dos vários grupos na sociedade, a empresa pode melhor atender as demandas do mercado. Consumidores conscientes, independentemente do grupo ao qual pertencem na sociedade, compram produtos e serviços das empresas que projetam uma imagem de diversidade. ${ }^{13}$ A promoção da diversidade e a aquisição de competências cross-culturais são fundamentais para o relacionamento da empresa não somente com os consumidores, mas também com todas as partes interessadas, da comunidade local até os governos estrangeiros nos países onde a empresa tem negócios. A vantagem competitiva de uma empresa será determinada em grande medida pela qualidade da relação que ela mantém com as pessoas, interna e externamente. $\mathrm{E}$ essa qualidade está diretamente relacionada ao problema da inclusão ou exclusão de diferentes grupos sociais (Instituto Ethos, dezembro 2003:25). Para que os negócios sejam espelhos de seus mercados, é preciso promover a diversidade dentro da empresa (Vassallo, 6/9/2000:104).

Inovação/Criatividade: A segunda justificativa pela promoção da diversidade é inovação/criatividade. A mistura de pessoas, de experiências e de idéias estimula a criatividade e permite que a empresa encontre soluções inovadoras para os desafios colocados pelo mercado e pela concorrência. Um grupo homogêneo terá mais dificuldade de vender para um mercado multicultural, global e cada vez mais segmentado que um grupo diverso. Nelson Savioli, o diretor de Recursos Humanos da empresa Unilever, aponta que 
"uma equipe formada só por homens, jovens, brancos freqüentadores das mesmas universidades, nas mesmas cidades, pode fazer um bom produto, mas uma equipe múltipla fará um produto excelente e, provavelmente, com menor custo e fará isso porque carrega muito mais informação" (ibidem:156). Bulgarelli observa que "Equipes marcadas pela diversidade são mais criativas, produtivas, inovadores, atraentes para talentos que chegam e ficam em nossas empresas, trazendo novas perspectivas para o conjunto e formando um 'mix' que traduz a contribuição de cada um, gerando uma sinergia que transcende essas contribuições individuais $(1+1=3)$ " (Bulgarelli, janeiro 2002:1). A promoção da diversidade também aumenta a qualidade do ambiente de trabalho e o relacionamento entre funcionários, que têm implicações importantes para a produtividade da empresa. Quando todos se sentem confortáveis na empresa e sentem que a empresa se preocupa com eles, isso aumenta a lealdade, o entusiasmo, a motivação; os funcionários dão o máximo de si, a produtividade fica melhor, e as taxas de rotatividade e de absenteísmo ficam muito menores (Somoggi, novembro 1999:114).

As justificativas pela promoção de diversidade partem de focos distintos. O conceito de diversidade, a partir do interesse econômico das empresas, visa à adequação a um mercado mais exigente em termos de imagem e desempenho, aglutinando eficiência e compromisso social; e, sob o ponto de vista da sociedade, visa à superação das práticas discriminatórias e de exclusão (Alexim apud Bellan, 2002:15). Mesmo assim, a promoção de diversidade voltada às políticas sociais de eqüidade e inclusão social e políticas econômicas de gestão de diversidade podem se complementar (Bento, 2002:58). No final de contas, tanto a empresa como a sociedade ganham com a promoção de diversidade no setor privado.

Correlação entre desempenho dos negócios e a valorização de diversidade: Esses argumentos em favor da promoção de diversidade são persuasivos, mas será que a promoção de diversidade traduz em benefícios econômicos para as empresas que abraçam essa idéia? Pois, diversidade é apenas um de um leque de fatores que impacta a produtividade e a rentabilidade de uma empresa. Cox, autor do livro Cultural diversity in organizations (1994), diz que as diferenças de identidade individuais (tanto físicas como culturais) interagem como uma complexa gama de fatores individuais, grupais e organizacionais (o clima da diversidade) para determinar o impacto da diversidade nos resultados individuais e organizacionais (Fleury, 2000:20). Um aumento na diversidade nas organizações provoca- 
rá impactos tanto em termos da eficácia organizacional como individual e o contexto organizacional é relevante para determinar se esse impacto será positivo ou negativo (idem).

A proposta não é simplesmente promover diversidade e pronto. Há uma ciência de gestão de diversidade que precisa ser estudada pelas empresas que assumem um compromisso com a promoção da diversidade para que seu impacto seja positivo. Segundo Maria Tereza Leme Fleury, da Faculdade de Economia e Administração da USP, o objetivo principal da gestão da diversidade racial é administrar as relações de trabalho, as práticas de emprego e a composição interna da força de trabalho a fim de atrair e reter os melhores talentos dentre os chamados grupos de minoria e adicionar valor à companhia (ibidem:21, 24).

Evidência empírica das empresas que efetivamente promovem e gerenciam diversidade tem mostrado que empresas que superam a discriminação, contratando e promovendo minorias e mulheres, são mais rentáveis (Ministério de Trabalho e Emprego, 2003:18). Por exemplo, num levantamento feito pela revista Fortune, as ações das 50 empresas americanas consideradas modelos de diversidade tiveram um desempenho muito superior à média do mercado de capitais (Vassallo, 6/9/2000:155). Segundo Christopher Wells, o analista de Investimentos Socialmente Responsáveis do Unibanco, "Não existe ainda nenhuma pesquisa científica que comprove a correlação entre empresas financeiramente bem-sucedidas e aquelas, social e ambientalmente responsáveis, mas verificamos que em mais de $50 \%$ dos casos, a relação é válida" (Instituto Ethos, 11/7/2001). Os critérios de avaliação das empresas e os procedimentos para ter acesso a esse capital variam muito, mas incluem a existência de mulheres na alta diretoria e os investimentos na diversidade (ibidem). A promoção da diversidade é uma das alavancas para melhorar o desempenho financeiro da empresa e atrair capital estrangeiro.

Diversidade e ação afirmativa: Concluindo essa seção, a promoção da diversidade significa considerar as diferenças como uma riqueza, como algo que adiciona valor na hora de tomar decisões, de realizar escolhas (Bulgarelli, 17/12/2003:slide 10). Olhar para a diversidade é também reconhecer que determinados grupos têm dificuldades históricas para se incluir na sociedade, diz a socióloga Rebecca Raposo, diretora executiva do Grupo e Institutos, Fundações e Empresas (Gife). "Eles terão de ser privilegiados por políticas sociais para que isso aconteça” (Loyola, 26/6/2003). Não há valorização de diversidade e mudanças reais na demografia interna 
das empresas sem ações afirmativas (Bulgarelli, 17/12/2003:slide 20).

Ação afirmativa é o conjunto de políticas públicas e privadas de caráter compulsório, facultativo ou voluntário concebidas com vistas à promoção de populações historicamente discriminadas e ao combate à discriminação. ${ }^{1 / 4}$ Requer um tratamento diferenciado a determinados grupos que se encontram em desvantagem na sociedade que não lhes permita ascender socialmente. "Ação afirmativa não é sinônimo de cotas. As cotas são não a única, mas uma das estratégias das açôes afirmativas" (Soares apud Bellan, 2002:22). Segundo Ivanir dos Santos, presidente da ONG CEAP, "Ação afirmativa é a empresa investir, dar bolsas e qualificar seus quadros, direcionando-se à população negra” (Herculano, 24/11/2003:1). No final desse relatório, considero os pontos de vista das empresas quanto ao conceito e à prática de ação afirmativa.

Ação afirmativa não é uma fonte de discriminação, mas veículo para remover os efeitos da discriminação. Sueli Carneiro, fundadora e dirigente do Geledés - Instituto da Mulher Negra, diz que o princípio que orienta a adoção de políticas de ação afirmativa - e um de seus instrumentos, as cotas para negros - se baseia num imperativo ético e moral de reconhecimento das desvantagens historicamente acumuladas pelos grupos raciais discriminados numa dada sociedade, que sustentam os privilégios de que desfrutam os grupos dominantes e explicam as desigualdades de que padecem os dominados (Carneiro, 2002:12). O consultor Reinaldo Bulgarelli reforça essa perspectiva ao declarar que é fundamental que os programas de promoção da diversidade tenham como método as ações afirmativas, meio pelo qual se pretende: 1) corrigir as situaçôes de desvantagem simbólicas e concretas enfrentadas por alguns segmentos da sociedade; 2) promover oportunidades iguais efetivamente para todos, tratando os desiguais de maneira desigual, ou seja, promovendo eqüidade (Bulgarelli, 17/12/2003:slide 11). Dadas as estatísticas apresentadas no início desse relatório, o uso de ações afirmativas e a inclusão de negros devem ser critérios básicos para qualquer programa de diversidade no contexto brasileiro (entrevista com Bulgarelli, 21/1/2004).

\section{Estudos de caso}

Tendências gerais: Meu levantamento identificou treze empresas com políticas e/ou práticas de promoção da diversidade que visam à inclusão de negros, entre outros grupos historicamente ex- 
cluídos. Esses casos foram avaliados em três dimensões: história e discussão da diversidade, prática/mecanismos de promoção da diversidade racial, e os resultados/impactos da promoção da diversidade racial. Não incluo, nesse artigo, o resumo de cada iniciativa, mas gostaria de fazer algumas constatações sobre tendências de programas de diversidade e mencionar algumas empresas que adotaram cotas de contratação para negros.

Enquanto estava pesquisando as iniciativas de diversidade no setor privado brasileiro, constatei que, apesar da natureza ampla da palavra diversidade, o conceito de diversidade adotado por essas companhias é geralmente restrito a um ou dois grupos de pessoas historicamente discriminados no mercado de trabalho. Freqüentemente, as mulheres e/ou os portadores de deficiência são $o(s)$ foco(s) da iniciativa da diversidade. Seguem abaixo alguns exemplos:

\begin{tabular}{|l|l|l|}
\hline Mulheres & Port. de Deficiência & (Múltiplo Grupos) \\
\hline Avon & Avape & ACS (port. de def., mulheres, terceira idade) \\
\hline General Electric & Prodam & Gelre (port. de def., presidiários) \\
\hline Mercedes-Benz & White Martins & Intermédica (port. de def., terceira idade) \\
\hline
\end{tabular}

Durante a revisão da literatura e as entrevistas, muitas outras empresas foram citadas como tendo um compromisso com a diversidade, mas não consegui confirmar a existência de uma política e/ou prática de promoção da diversidade nessas empresas utilizando os recursos disponíveis. ${ }^{15}$ Pode-se dizer que as empresas com iniciativas de diversidade acham mais fácil promover a inclusão/ascensão de mulheres e portadores de deficiência do que a inclusão/ascensão dos negros. Parte da explicação é que as mulheres, equivalentes a $50,3 \%$ da população, representam $54,3 \%$ dos que têm nível superior - um dos requisitos essenciais de muitas empresas. ${ }^{16}$ Quanto aos portadores de deficiência, há uma lei que diz que todas as companhias com mais de cem funcionários estão obrigados a preencher de $2 \%$ a $5 \%$ dos seus cargos com portadores de deficiência (Buchalla e Martins, 7/6/2000:118).

Outra constatação do meu levantamento de iniciativas de diversidade é a existência de cotas de contratação em três empresas. Esses casos não foram analisados em detalhe porque duas das empresas não estão dentro do âmbito geográfico dessa pesquisa (São Paulo e Rio de Janeiro) e a outra empresa adotou cotas tão re- 
centemente que não deu tempo para pesquisá-la. Por estes casos representarem um dos tipos de ação afirmativa, é importante incluí-los aqui.

Cotas para afrodescendentes nas empresas: Em 1999, a Prefeitura de Porto Alegre firmou um acordo com a rede de hipermercados Zaffari para que a empresa garantisse a contratação de no mínimo $5 \%$ de empregados negros como condição para uma nova loja na cidade (Heringer, 2000:315). O acordo diz que as vagas não poderão ser apenas em postos de menor remuneração (idem). A empresa Ford implantou uma fábrica em Camaçari, Bahia, em outubro de 2001 , e estabeleceu uma meta mínima de $40 \%$ de mulheres e $70 \%$ de afrodescendentes em suas contratações, de acordo com a proporção desses grupos na população regional (Imprensa Ford, março de 2002:1-2). O presidente da Ford no Brasil, Antonio Maciel Neto, disse, "Estamos comprometidos com as ações afirmativas. Elas não são positivas só para os afrodescendentes, mulheres e deficientes; elas são benéficas para toda a sociedade" (ibidem:2). É importante anotar que a Ford procura reproduzir no chão da fábrica (ênfase minha), na medida do possível, a mesma composição cultural, étnica e sexual da região onde está instalada, diferente do acordo entre a Prefeitura de Porto Alegre e a rede Zaffari, que exige contratação não somente no nível funcional da empresa (Sigollo, 2001:149). O mais recente exemplo de cotas de contratação de negros ocorreu em São Paulo, em janeiro de 2004. Lá , um acordo entre o Sindicato dos Comerciários, filiado à Força Sindical, fechou um acordo com a rede de lojas Camisaria Colombo estabelecendo que $20 \%$ das vagas da empresa serão para negros (Diário de São Paulo, 10/1/2004).

\section{Conclusão}

Resultados

Ao começar essa pesquisa, eu postulava que as únicas empresas com iniciativas de promoção da diversidade racial fossem subsidiárias de empresas estrangeiras, especificamente norte-americanas, e que essas filiais brasileiras só assumiram um compromisso com a promoção da diversidade racial porque a matriz exigiu a criação de programas desse tipo. Algumas das informações que eu colhi por meio da revisão de literatura e as entrevistas me surpreenderam. Para poder comparar as iniciativas e as empresas que as administram, criei uma matriz. Os nomes das empresas se 
INICIATIVAS DE PROMOÇÃO DA DIVERSIDADE RACIAL NO SETOR PRIVADO

Fevereiro 2004

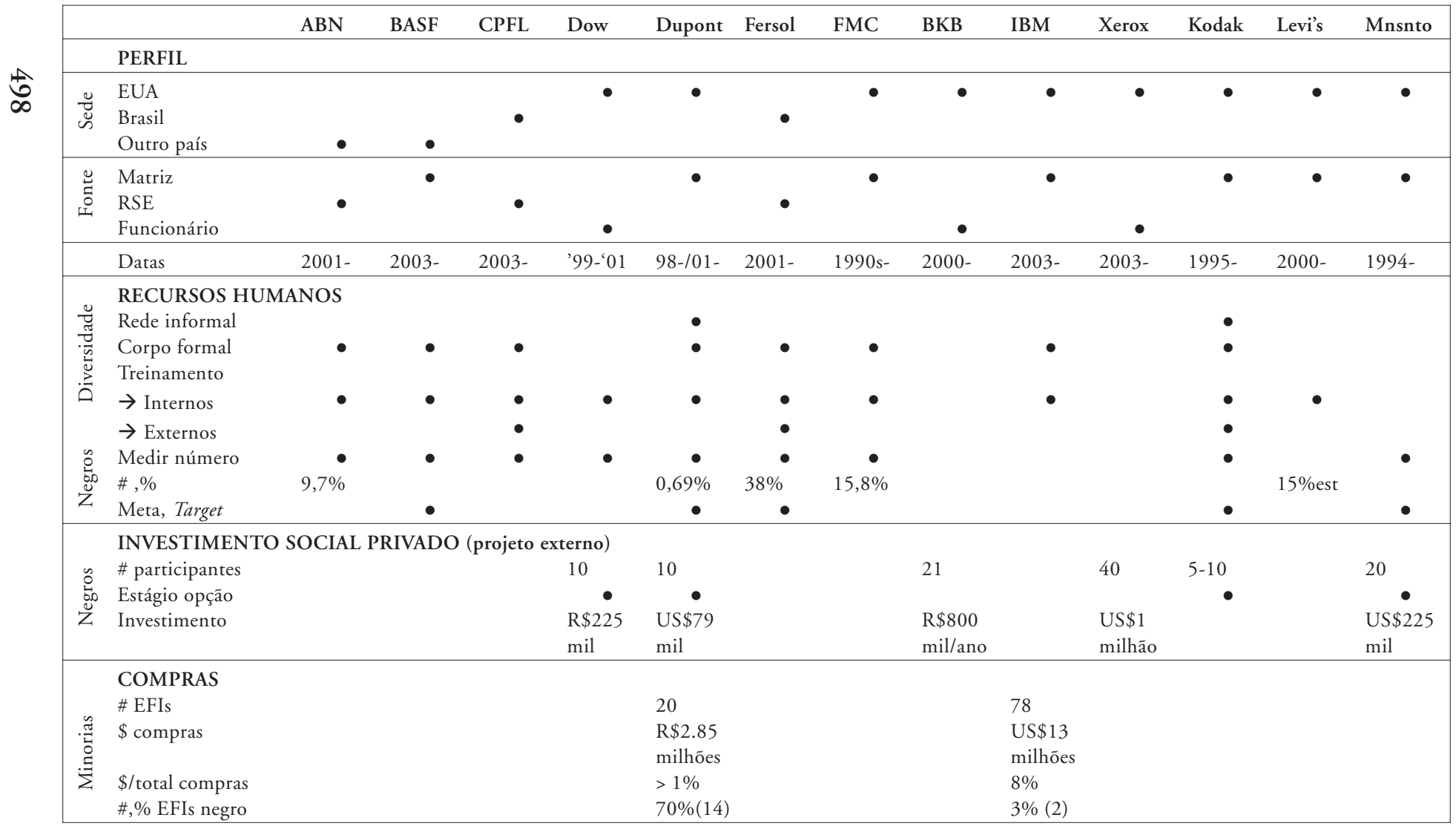

ABN - ABN Amro / Banco Real

BKB - Fundação BankBoston

Mnsnto - Monsanto

RSE - responsabilidade social empresarial

EFIs - empresas fornecedores de integração (empresas pertencentes a negros, indígenas, ou portadores de deficiência) 
encontram na parte superior da matriz e, no lado esquerdo desta, os critérios de comparação estão baseados, em parte, nos Indicadores Ethos, uma ferramenta para avaliar responsabilidade social. Nos seguintes parágrafos, farei uma série de constatações sobre as tendências reveladas pela matriz e pelos estudos de caso. Concluirei minha análise apresentando minhas recomendaçóes para as empresas atuais e futuras que querem realizar o valor (em termos éticos e econômicos) repleto de diversidade racial.

\section{Observações}

A maioria das empresas com uma iniciativa de promoção da diversidade racial estão sediadas nos Estados Unidos, e a maioria delas têm iniciativas em função de políticas/programas de diversidade na matriz. Chama a atenção o fato de que duas delas são empresas nacionais. Também foi interessante aprender que três das iniciativas são únicas e existem somente no Brasil. As outras três iniciativas são oriundas de um compromisso da empresa com a responsabilidade social empresarial (RSE).

Um estudo recente sugere que as preocupações de responsabilidade social com questôes sociais e ambientais ajudam a sensibilizar a empresa para a diversidade. O IPEA fez um cruzamento dos dados da pesquisa Ação Social das Empresas com os da RAIS (Relação Anual de Informações Sociais) para saber se as empresas que praticam ação social contratam proporcionalmente mais negros; para as empresas que fazem algum tipo de ação social, a média é um trabalhador negro para dezessete brancos, e para as empresas que não fazem nenhum tipo de ação social essa relação é de um para 22 (GIFE, 11/11/2002). Entidades que defendem os interesses dos negros também desempenharam um papel importante ao colocarem em pauta o assunto da diversidade racial nas empresas. A partir de 1997, por iniciativa de membros do movimento negro, desenvolveram-se algumas açóes que visavam ao contato com empresas norte-americanas que aplicavam políticas de diversidade em suas matrizes, mas discriminavam negros nas filiais brasileiras (Bento, 2000:27).

Retornando à matriz, a maioria das iniciativas de diversidade são recém-lançadas, ${ }^{18}$ e embora todas as empresas declarem que diversidade ou respeito às pessoas e/ou diferenças é um valor corporativo, a maneira como elas valorizam a diversidade racial varia bastante. Geralmente, as empresas procuram promover a diversi- 
dade racial em uma ou mais de três áreas: recursos humanos, investimento social privado, e/ou compras. As duas na área de compras têm uma parceria com a ONG Integrare e valorizam a diversidade por apoiar as atividades da Integrare e compra bens e serviços de fornecedores cujos donos são negros ou membros de outras minorias (as chamadas EFIs - Empresas Fornecedores da Integração). $\mathrm{Na}$ área de Investimento Social Privado, quase metade apóia financeiramente bolsas de estudos e/ou programas de educação para jovens negros que geralmente oferecem oportunidades para fazer um estágio na empresa afiliada. Apesar de beneficiar um grupo relativamente pequeno de estudantes e fornecedores negros, tanto as iniciativas na área de compras como as na área de investimento social privado são compromissos de longo prazo. Neide Fonseca, do INSPIR, comentou que a maioria das iniciativas de diversidade nas empresas não altera a realidade e são tímidas em relação à magnitude do problema (entrevista com Fonseca, 15/12/2003). Mas John Jansen, da DuPont, sugeriu que se outras empresas tomassem essas iniciativas como um exemplo e fizessem a mesma coisa, faria uma diferença (entrevista com Jansen, 21/1/2004).

\section{Recomendações}

Não dá para dar uma receita para um programa de diversidade (entrevista com Bulgarelli, 21/1/2004). Mas, refletindo sobre os casos nessa pesquisa, posso oferecer algumas dicas para ingredientes importantes para iniciativas da promoção da diversidade racial. Organizei essas recomendações em quatro categorias, as mesmas utilizadas nos estudos de caso: História e Discussão, Prática, Impacto, e Comentários. Muitas das minhas recomendações são uma reflexão daquelas feitas pelo Instituto Ethos e incluem: ${ }^{19}$

1) criar um comitê/conselho de diversidade,

2) realizar treinamentos internos e externos (com fornecedores),

3) iniciar um diálogo/criar parcerias com entidades do terceiro setor e com outras empresas sobre e para a promoção de diversidade,

4) buscar alinhamento entre ações externas e ações internas na promoção da diversidade,

5) mensurar o número de minorias no quadro de funcionários, 
6) estabelecer metas específicas de longo prazo para aumentar a presença dessas minorias na empresa em todos os níveis,

7) oferecer incentivos financeiros aos gestores para cumprirem essas metas,

8) adotar açôes afirmativas.

História e Discussão: Analisando a história das treze empresas, muitas das iniciativas contaram com o apoio da direção da empresa durante as fases iniciais. Segundo o superintendente de FMC, "se os líderes da empresa não se convencerem de que a diversidade dá resultados melhores, o processo não caminha" (Vassallo, 6/9/2000:160). Além da direção, é fundamental que os outros funcionários estejam comprometidos com a promoção da diversidade. Para fazer isto acontecer, é preciso criar um corpo formal (um comitê ou um conselho de diversidade) que administre as atividades de promoção de diversidade, e realizar treinamentos regulares para sensibilizar os funcionários sobre o valor da diversidade (veja a próxima seção). Alguns dos papéis do comitê/conselho de diversidade são construir uma agenda e metas de acordo com a realidade da empresa e da comunidade em que está inserida, coordenar a implementação do programa, acompanhar e avaliar o progresso do programa, e revisar/aperfeiçoar as atividades para realizar os objetivos do programa.

Prática: Outro papel do comitê/conselho de diversidade deve ser organizar palestras, oficinas, fóruns e/ou treinamentos para sensibilizar os funcionários sobre culturas diferentes e sobre os benefícios da diversidade. Na minha opinião, eles são tão importantes para os resultados das iniciativas de promoção da diversidade quanto a direção, porque eles são responsáveis pela implementação das atividades. Se eles não forem convencidos do valor da diversidade, não vão implementá-la com muito vigor, e o resultado será muito menos do que esperado. Muitas empresas nessa pesquisa registraram dificuldades em realizar os objetivos das iniciativas de diversidade, e nos casos das filiais americanas não é incomum que as pessoas vejam nessa questão da diversidade a importação de um problema que não tem nada a ver com a realidade brasileira (Esteves, 1999:7). Para mudar esse ponto de vista, mais da metade das empresas realizaram treinamentos, palestras, e fóruns internos sobre diversidade e, em alguns casos, o foco da discussão foram os negros. 
Algumas empresas foram além do público interno, visando engajar os fornecedores na promoção da diversidade. $\mathrm{Na}$ área de compras, IBM e DuPont informalmente encorajam os fornecedores a identificar e comprar das EFIs. A Fersol enviou uma exigência formal às empresas terceirizadas pedindo que lhe enviassem currículos de candidatos negros, e o CPFL realiza oficinas práticas com seus fornecedores para ajudá-los a diversificar suas fontes de recrutamento para que haja mais candidatos das minorias. O ABN-Amro/Banco Real foi a primeira empresa a criar um banco de currículos de candidatos negros e, assim como a Fersol e o CPFL, divulgam suas vagas pelas entidades negras, fontes nas quais essas empresas anteriormente não buscavam candidatos.

Entidades negras não devem ser vistas apenas como meios de divulgação de oportunidades, mas como parceiros potenciais na promoção da diversidade. Além das parcerias existentes entre entidades negras e empresas, Kodak e IBM estão construindo novas parcerias com o Afrobras e o QualiAfro, por exemplo. ${ }^{20}$ As empresas podem e devem iniciar um diálogo com entidades negras e com outras empresas com o objetivo de disseminar a cultura de promoção da diversidade racial no setor privado. A Shell, por exemplo, possui um Grupo Empresarial de Valorização da Diversidade que tem representantes de 35 empresas diferentes e fazem três reuniões por ano. O professor Hélio Santos, do CEERT, e um representante do QualiAfro falaram sobre estratégias para a inclusão dos negros nas empresas durante uma reunião recente (entrevista com Kepler, $4 / 2 / 2004)$. Diálogos e parcerias deste tipo sugerem que a promoção da diversidade não tem necessariamente que ser um processo de cima para baixo, mas que pode ser de baixo para cima.

Minha última recomendação com respeito à promoção da diversidade na prática é que as empresas busquem um alinhamento entre suas ações internas e externas com relação à promoção da diversidade. Se a diversidade é um valor da empresa, ela deve ser difundida por todas as áreas da empresa e deve marcar a forma de agir da organização em sua totalidade. Olhando para a matriz na categoria de recursos humanos e a de investimento social privado, vemos que empresas como DuPont e Kodak apóiam programas bolsa-estágio para jovens negros $e$, dentro da empresa, têm corpos formais e informais de diversidade e realizam atividades de sensibilização sobre diversidade. Por outro lado, empresas como Dow, Fundação BankBoston e Xerox também investem em programas de educação fora da empresa, mas não têm, dentro dela, corpos 
estruturados, nem atividades voltadas para a promoção da diversidade.

Ivanir Santos, do CEAP, diz que não basta investir na diversidade fora da empresa e não promover diversidade dentro da empresa também (entrevista com Santo, 2/2/2004). O consultor Reinaldo Bulgarelli fez comentários semelhantes, dizendo que é esquisito para uma empresa investir num grupo historicamente discriminado fora da empresa e não contratar membros daquele grupo para trabalhar dentro da empresa (entrevista com Bulgarelli, $21 / 1 / 2004)$. Dois dos entrevistados acharam que as atividades comerciais da Monsanto com transgênicos são contraditórias ao conceito de responsabilidade social è iniciativa de diversidade da empresa, o Projeto Afro-Brasileiro (entrevistas com Fonseca e Oliveira, 15/12/2003 e 15/1/2004, respectivamente).

Das empresas incluídas nessa pesquisa, quem mostrou o melhor alinhamento entre o valor, o discurso e a prática da promoção da diversidade racial foi a DuPont, com atividades em todas as áreas de atuação identificadas: recursos humanos, investimento social privado e compras. Por outro lado, tem a Levi's. Apesar de ter políticas de valorização da diversidade, a Levi's realizou poucas atividades para concretizar a diversidade e nem tem material escrito sobre o assunto porque, segundo representantes de recursos humanos, "[a diversidade] é algo muito natural na Levi's" (entrevista com Padilha e Staich, 27/1/2004).

Impacto: Minhas recomendações para melhorar o impacto das atividades de promoção da diversidade dizem respeito à mensuração e aos incentivos à diversidade racial. Na segunda subcategoria de recursos humanos da matriz, vemos que além de estimular a participação dos negros nos programas de estágio e de capacitação dentro da empresa, mais da metade das empresas sabem o número de funcionários negros, mas nem sempre monitoram mudanças nesse número e/ou não sabem em que patamar da hierarquia os negros estão. Duas empresas, a Fundação BankBoston e a Levi's, não medem o número de funcionários negros porque acham que isso seria discriminatório.

Ainda estamos longe da igualdade porque as empresas têm medo de corrigir a situação, pensando que estão discriminando por pedir aos seus funcionários que indiquem sua cor/raça (Herculano, 22/7/2002). Para saber seu desempenho na promoção da diversidade, o Instituto Ethos diz que é fundamental "realizar um acompanhamento das informações a respeito de seus empregados, identificando as discrepâncias e mudanças nas situações compara- 
tivas de mulheres, negros ou outros grupos relevantes para a empresa" (Instituto Ethos, dezembro de 2003:28). Segundo Reinaldo Bulgarelli, "uma organização que divulga a idéia de que somos todos diversos não tem problemas em identificar as pessoas, nem as pessoas se sentem ameaçadas com isso" (Herculano, 22/7/2002). O primeiro passo para uma iniciativa de promoção da diversidade deve ser saber quantos são e em que nível estão os funcionários de grupos historicamente discriminados.

Para garantir que a iniciativa da diversidade alcance seus objetivos, é preciso estabelecer metas específicas de longo prazo e oferecer incentivos concretos para as pessoas responsáveis pela implementação das atividades. Por isso, o Instituto Ethos recomenda que as empresas adotem a diversidade como um parâmetro orientador das políticas de desenvolvimento e remuneração das pessoas da empresa (Instituto Ethos, dezembro de 2003:28). Para duas empresas, IBM (compras) e Monsanto, o desempenho na promoção da diversidade é um dos parâmetros da avaliação periódica dos gestores (idem). No caso da IBM, o gerente de compras Brasil tem um objetivo anual para a diversidade entre os fornecedores (o número de EFIs - Empresas Fornecedoras de Integração) que aumenta a cada ano, e uma parte de seu bônus depende do cumprimento dessa meta. É impressionante observar que quem alcançou os melhores resultados na promoção da diversidade dentro da empresa é uma empresa brasileira — a Fersol. Trinta e oito por cento dos funcionários da empresa são negros.

Comentários: Termino este relatório com algumas constatações sobre os comentários dos entrevistados. Quando perguntado sobre as justificativas da promoção da diversidade, a maioria citou os benefícios econômicos. Duas exceções foram a Dow, que mencionou solidariedade, e a Fersol, que falou da necessidade de corrigir uma injustiça de séculos quanto ao gênero e à raça. No final das contas, os motivos importam menos do que as açôes concretas das empresas e a inclusão efetiva dos negros e outros grupos historicamente discriminados no mercado de trabalho.

Os comentários dos entrevistados refletem uma certa nebulosidade sobre o que constitui ação afirmativa na prática. Essa pesquisa constatou várias práticas empresariais voltadas especificamente para os negros, ${ }^{21}$ mas, na minha opiniāo, poucas delas podem ser chamadas ações afirmativas. Por exemplo, a incubação/tutoria de fornecedores ou estagiários negros mencionada por algumas empresas já fazia parte do trabalho delas com fornecedores e estagiários independentemente do perfil deles, e não tinham/têm 
como objetivo a superação das desvantagens historicamente acumuladas pelos grupos raciais discriminados. Considerando o segundo critério de ação afirmativa - tratamento desigual dos desiguais - para favorecer somente a mulheres ou negros em casos de empate, não passa por ação afirmativa. Uma das maneiras para tratar de uma maneira desigual os desiguais é reservar vagas para pessoas dos grupos historicamente discriminados, mas nenhum dos entrevistados aprovou da idéia de cotas. A DuPont declarou que cotas representam uma desigualdade necessária para que haja condições de igualdade, mas não tem cotas de contratação. Por outro lado, a IBM reforça cotas para portadores de deficiência (em função da lei), mas nunca adotou cotas para outros grupos.

Então, o que é ação afirmativa, na prática? Na minha opinião, programas como o Programa Afro-Brasileiro, da Monsanto, o Geração XXI, da Fundação BankBoston, e o Afro-Ascendentes, do Instituto Xerox, podem ser qualificados como ação afirmativa. São investimentos sociais privados, dirigidos aos negros com o objetivo de dar-lhes condições para superar as barreiras históricas e contemporâneas na sociedade brasileira.

Dentro de uma empresa, posso citar um exemplo de ação afirmativa na prática: a Fersol montou um banco de dados com currículos de mulheres, negros, portadores de deficiências e de pessoas com mais de 45 anos; cada nova vaga que a empresa abrir é oferecida prioritariamente para as pessoas qualificadas desses grupos. Se a vaga não for preenchida, só então é divulgada para outras pessoas (Instituto Ethos, janeiro de 2002). Na hora de contratação, a Fersol segue uma regulamentação interna para privilegiar pessoas historicamente excluídas na seguinte ordem: $1^{\circ}$ ) mulheres; $2^{\circ}$ ) negros/afrodescendentes; $3^{\circ}$ ) portadores de talentos especiais; e $4^{\circ}$ ) pessoas com mais de 45 anos), mesmo quando o candidato com esse perfil seja menos qualificado que um candidato com um perfil tradicional. Por exemplo, se tivesse um candidato tradicional com 100 pontos e outro candidato geralmente excluído com 80 pontos, a Fersol vai selecionar o candidato excluído. Se o candidato excluído tivesse 50 pontos, é provável que a Fersol não desse preferência ao segundo candidato (entrevista com Manchesski e Haradom, 6/2/2004).

Hoje, na Fersol, pessoas de grupos historicamente discriminados estão representadas nas seguintes porcentagens: mulheres $71 \%$; negros - 38\%; portadores de talentos especiais - 3\%; e pessoas com mais de 45 anos $-20 \% .{ }^{22}$ A razão de a Fersol ter obtido resultados tão impressionantes na promoção da diversidade se deve a 
que a empresa adotou ações afirmativas. Essa evidência empírica reforça a declaração feita no final da primeira seção desse relatório: não há promoção de diversidade sem ação afirmativa.

\section{Conclusão}

Concluindo, é fácil dizer que não discrimina e que valoriza a diversidade, mas colocar esse valor na prática e realmente diversificar o quadro de funcionários são tarefas bastante difíceis. Os comentários dos entrevistados refletem essa dificuldade; segundo Wagner Celeste - Gerente de Recursos Humanos da CPFL, "iniciar um programa não quer dizer iniciar uma prática, há uma dificuldade/distância entre a proposta e a prática. O CPFL não tinha noção da profundidade do processo de criar um programa de diversidade" (entrevista com Celeste, 20/1/2004). E o superintendente de FMC disse, "quem aposta na ação afirmativa tem de estar preparado para despertar conflito e lidar com frustrações" (Vassallo, 1995:74). Não é fácil para uma corporação madura, com pouca diversidade, mesclar-se rapidamente (Zachary, 6/9/2000). É um processo lento de mexer na estrutura e processos internos das empresas para que haja mais diversidade (Bulgarelli, 17/12/2003). Uma mudança nesse sentido não acontece do dia para a noite, é um processo de longo prazo (Somoggi, novembro de 1999:114).

Mas há que acreditar que enfrentar essas dificuldades e frustrações vai valer a pena. Apostar na diversidade, e especificamente na diversidade racial, é contribuir para uma sociedade mais justa e uma economia mais competitiva. Parabenizo essas treze empresas que estão caminhando nesse sentido. Tomara que minha pesquisa contribua para o aperfeiçoamento e expansão das suas iniciativas e inspire outras empresas a abraçarem o valor, tanto ético como econômico, da diversidade.

\section{Notas:}

1. O método de determinar a cor no Brasil é autodeclaratório; a pessoa define sua cor ou raça. As categorias utilizadas são as de IBGE: preto, pardo, branco, índio, e amarelo.

2. A segunda estatística vem da Pesquisa Nacional por Amostra de Domicílios (PNAD) de 1999.

3. Pesquisa realizada em 1998 pelo INSPIR - Instituto Sindical Interamericano pela Igualdade Racial, Fundação Seade - Sistema Estadual de Análise de Dados, e DIEESE - Departamento Intersindical de Estatísticas e Estudos Sócio-Econômicos. 
4. O Instituto Ethos é uma associação sem fins lucrativos, que visa mobilizar, sensibilizar e ajudar as empresas a gerirem seus negócios de forma socialmente responsável. Site: http://www.ethos.org.br/docs/institucional/perguntas.shtml.

5. As não-respostas à pergunta sobre cor ou raça dos funcionários oscilaram entre $23 \%$ e $27 \%$. Isso indica haver certa dificuldade nas empresas para tratar do assunto (Instituto Ethos dezembro 2003: 15). As empresas também têm tido dificuldade em cumprir a Portaria do Ministério do Trabalho (1.470/99) que determina que o empregador deve informar raça/cor dos empregados na declaração da RAIS (Relação Anual de Informações Sociais, Bulgarelli julho 2002: 11). É um censo que todas as organizaçōes deve preencher anualmente 1999 foi o primeiro ano em que o quesito raça/cor foi incluído no formulário (GIFE, 11/11/2002). A inclusão da raça/cor no formulário foi questionada como uma prática racista (Herculano, 22/07/2002; Bulgarelli, 17/12/2003).

6. Essas empresas são: Variglog. Citibank, e Fundação BankBoston. "Segundo Dagoberto Campigoto do RH [de Variglog], houve algumas iniciativas sobre o assunto na empresa, mas não tiveram continuidade. E não havia nada muito estruturado. Quem cuidava disso era uma subgerente, Renata Cota, que se especializou no tema. Mas ela saiu da empresa para desenvolver um trabalho sobre diversidade numa universidade em New Orleans, nos EUA, focalizando a América Latina”. (e-mail de Benjamin S. Gonçalves, Gestão da Informação, Instituto Ethos, São Paulo, no dia 27/1/2004).

7. Palavras de um dos representantes das empresas participantes do Encontro Tripartite sobre Implementação de Políticas Voltadas à Diversidade em São Paulo em 1996.

8. Palavras de Felipe Westin, então diretor de recursos humanos de Monsanto.

9. Site: http://www.ethos.org.br/docs/institucional/perguntas.shtml.

10. Site: http://www.ethos.org.br/docs/institucional/perguntas.shtml.

11. Combate à discriminação é aqui justificada pela ética, mas poderia ser justificada por razões econômicas também, pois discriminação causa prejuízos econômicos. Segundo Sueli Carneiro, a urgência em implementar políticas para promover a igualdade racial no país atende a um imperativo de ordem econômica, na medida em que a exclusão dos negros do desenvolvimento conduziu o Brasil a uma situação de aleijamento de metade de sua população dos processos de desenvolvimento-comprometendo a capacidade competitiva do país diante de outras naçôes do mundo, numa conjuntura em que um dos principais ativos econômicos é uma base social ampla, educada, em condições de se apropriar do desenvolvimento cultural e tecnológico, que resulta em maior produtividade, maior competitividade, e melhores condições de consumir (Carneiro 2002: 13-14.).

12. Fonte original: Instituto Ethos (dezembro 2003:26-27).

13. Segundo Oded Grajew, fundador do Instituto Ethos, estudos mostram que as empresas que usam a responsabilidade social apenas como marketing correm grandes riscos. Elas vão enganar durante determinado tempo, mas quando esse engano é revelado os resultados são danosos (Observatório Social outubro 2003: 42). Neide Fonseca do INSPIR mencionou dois casos interessantes. Banco Itaú lançou cheques com foto de famílias negras, mas raramente contratam negros para trabalhar no banco. Ela falou que Ceda introduziu produtos de beleza negra, mas utilizou termos in- 


\section{Aaron Myers}

sultantes como "cabelos negroides" durante a pesquisa que levou a criação dos produtos (Entrevista com Fonseca no 15/12/2003).

14. "Ação Afirmativa Atitude Positiva" 2003 (folheto).

15. Iniciativas de diversidade não identificadas: Banco Chase Manhattan, CIA, Citibank, Coca-Cola, Compaq, Cummins, Elma Chips, General Motors, Gessy Lever, Intel, Johnson \& Johnson, JP Morgan, Lucent, Motorola, Natura, Novatis-Agro, Pão de Açúcar, Procter \& Gamble, Seiko, e Wal-Mart.

16. Escóssia (3/12/2003). Segundo dados do IBGE, citado durante entrevista com Pacheco, em 16/12/03.

17. Esta lei, de 1999, nem sempre é cumprida.

18. A iniciativa da Monsanto, o Projeto Afro-Brasileiro, é uma das mais antigas e precedeu à iniciativa do programa Geração XXI, da Fundação BankBoston, que muitos chamavam a primeira iniciativa empresarial de ação afirmativa para negros, por cinco anos.

19. Duas referências excelentes do Instituto Ethos são: "Perfil social, racial e de gênero das 500 maiores empresas do Brasil e suas ações afirmativas" (dezembro 2003); e "Como as empresas podem (e devem) valorizar a diversidade" (setembro de 2000).

20. As parcerias existentes incluem: Integrare com DuPont e IBM, Geledés com a Fundação BankBoston e o Instituto Xerox, CEAP com o Instituto Xerox, e Banco Real com o CEERT.

21. Atividades observadas: diversificação das fontes de recrutamento e seleção (através de divulgação de vagas para entidades negras, oficinas de sensibilização para os fornecedores/empresas terceirizadas, e pedidos formais [às empresas terceirizadas ou nos anúncios de jornais] para candidatos negros), fóruns ocasionais que convocam funcionários e representantes de entidades negras, comemoração de feriados de interesse da comunidade negra (Dia Nacional da Consciência Negra, Dia Internacional de Combate ao Racismo etc.), criação de um banco de currículos de candidatos negros e encaminhamento desses currículos para diretores regionais, e tutoria de fornecedores ou estagiários negros, investimento social privado em programas de capacitação/educação para negros etc.

22. Entrevista com Manchesski e Haradom, da Fersol, 6/2/2004. Os números aqui apresentados somam mais que $100 \%$ porque alguns funcionários pertencem a mais de um grupo.

\section{Referências Bibliográficas}

ABRAHÃO, Júlia I. e ALMEIDA, Angela M.O. (1999). Diversidade: gestão e capacitação da força de trabalho.

ALEXIM, J. (1999). "A diversidade no âmbito da educação profissional e do mercado de trabalho". Revista Internacional do Trabalho. Brasília, Ed. Projeto OIT/TEM.

(1999). As questôes de diversidade e o papel da educação profissional. Brasília, OIT.

ALMADA, Sandra (2003). "Mãos à obra: empresários negros driblam dificuldades e com muito trabalho começam a trocar salários por lucros como empreendedores de sucesso". Raça, Ano 7, no 71, novembro/dezembro, pp. 58-62. 
AMCE (2003). "Valorização, promoção e gestão da diversidade". São Paulo, AMCE. Site: www.amce.com.br/comoãatuamosãdetalhe.asp?atuãID=9, seção Como Atuamos.

BANCO REAL. Site: www.bancoreal.com.br, seções Responsabilidade Social e Oportunidades.

BARBOSA, L. (2001). "A diversidade no seu devido lugar”. In C. Vassallo, Guia Exame de boa cidadania corporativa. São Paulo, Editora Abril, v. 754, pp. 40-42.

BASF (2003). "BASF lança conceito de diversidade no Brasil". Informativo Gerencial: Edição Especial. São Bernardo do Campo, julho. Documento interno. (2003). "Diversidade, a química da diferença". BASF Notícias, Ano XXVI, no 301, novembro/dezembro, p. 14 (jornal da empresa). (2003). "Visão EC Missão". São Bernardo do Campo, Folheto. (2003). "Visão 2010, valores e princípios do Grupo BASF”. São Bernardo do Campo, Folheto.

BELLAN, Ana Clara (2002). "Diversidade e discriminação". In J. Dias \& L. Freire (orgs.), Diversidade: avanço conceitual para a educação profissional e o trabalho. Ensaios e reflexôes. Brasília, OIT, pp. 15-24.

; ALEXIM, João Carlos; DIAS, Jussara \& FREIRE, Luciene (orgs.) (2002). Referencial de planejamento: diversidade e educação profissional. Brasília, OIT.

BENTO, Maria Aparecida da Silva (2002). Pactos narcísicos: branquitude e poder nas organizaçôes empresariais e no poder público. Dissertação de Doutorado, São Paulo, Instituto de Psicologia de São Paulo, 169 pp.

(2002). "Raça-Cor/Etnia: reflexões sobre programas de diversidade no Brasil". In J. Dias e L. Freire (orgs.), Diversidade: avanço conceitual para a educação profissionale o trabalho: ensaios e reflexões. Brasília, OIT, pp. 49-61.

(2000). "Tratamento da diversidade na área de recursos humanos”. Gênero no Mundo do Trabalho, I Encontro de Intercâmbio de Experiências do Fundo de Gênero no Brasil, Fundo para a Equidade de Gênero, da Agência Canadense para o Desenvolvimento Internacional (CIDA). Brasília.

(2000). "Igualdade e Diversidade no Trabalho". In M. A. da S. Bento (org.), Ação afirmativa e diversidade no trabalho: desafios e possibilidades. São Paulo, Casa do Psicológico, pp. 11-32.

(1999). "Igualdade e diversidade no trabalho". Revista Latinoamericana de Estudios del Trabajo, Ano 5, no 10, pp. 121-133.

_ (1998). "Os psicólogos de RH: a igualdade e a diversidade no trabalho". Jornal do Federal, Ciência \& Ética, Ano XIII, no 56, dezembro, p. 6.

_ (1998). Racismo no trabalho: o lugar do movimento sindical e do Estado. São Paulo, mimeo.

\& CASTELAR, Marilda (orgs.) (2001). Inclusão no trabalho: desafios e perspectivas. São Paulo, Conselho Regional de Psicologia.

BUCHALLA, Anna Paula e MARTINS, Juliana (2000). "Cotas de 10\% - Empresas multinacionais estão reservando vagas para minorias. Principalmente Negros”. Veja, Ano 33, no 23, 7 de junho, pp. 118-119.

BULGARELLI, Reinaldo (consultor de AMCE Negócios Sustentáveis) (2003). Apresentação na oficina "Políticas de Valorização da Diversidade no Trabalho: constru- 


\section{Aaron Myers}

indo uma agenda". Seminário "Desafios das Políticas Públicas de Promoção da Igualdade Racial”. São Paulo, SESC Vila Mariana, 16 e 17 de dezembro. Coordenação do Centro de Estudos das Relações de Trabalho e Desigualdades.

(2002). "A diversidade e a empresa moderna". São Paulo, AMCE, janeiro. Site: www.amce.com.br/opinioes.htm, seção Valorização de Diversidade.

(2002). "Valorização, promoção e gestão da diversidade: desafios para as organizações no século XXI". São Paulo, AMCE, julho. Site: www.amce.com.br/opinioes.htm, seção Valorização de Diversidade.

(2001). "Paz, tolerância e diversidade". Conferência Magna: IV Conferência dos Direitos da Criança do Adolescente do Ceará. Fortaleza, AMCE, outubro. Site: www.amce.com.br/opinioes.htm, seção Valorização de Diversidade.

(2001). "Diversos somos todos". (Folheto resumindo uma palestra). São Paulo, Banco Real/ABN-Amro, novembro.

_ (s/d). "Diversidade e responsabilidade social das empresas". UNESCO, Seminário Nacional Cultura de Paz, Transdisciplinaridade e Direitos Humanos: Cultura e Paz - Distintos Olhares. São Paulo: Fundação BankBoston. Site: www.amce.com.br/opinioes.htm, seção Valorização de Diversidade.

CAMPOS, Stela (2002). "Descobrindo os melhores talentos entre os que têm menos oportunidades". Valor Econômico, 22 de janeiro.

CARBONE, Geraldo (Presidente do BankBoston Brasil). "O poder da diversidade”. Revista Exame.

CARNEIRO, Sueli (2002). "Expectativas de ação das empresas para superar a discriminação racial”. Reflexão, Ano 3, no 8, setembro.

CEAP (2003). "Ação afirmativa, atitude positiva”. Rio de Janeiro, CEAP, folheto.

CEERT - Centro de Estudos das Relações de Trabalho e Desigualdades. Site: www.ceert.org.br

CIEE - Centro de Integração Empresa-Escola (2003). "Parceria CIEE e Monsanto Fund/Projeto Afro-Brasileiro/Exercício de 2003 - $1^{\circ}$ Semestre”. São Paulo, CIEE. Relatório interno do progresso do programa.

_ (2000). "Parceria para desenvolver talentos". Agitação, Ano VI, no 34, julho/agosto, pp. 43-45, publicação do CIEE Nacional.

CIEDS (2003). "Afro-ascendentes". Site: www.cieds.org.br/estatico.asp?arq=projetoãascendentes, seção Projetos/Educação para o Desenvolvimento.

CPFL. (2004). Expresso: Jornal da CPFL Energia, Ano 2, n. 67, 9 de janeiro (documento interno).

_ (2003). “Esta é uma empresa que valoriza a diversidade". Site: www.cpfl.com.br/new/conhecaãenergia/recursos.asp (2003). Respeito às diferenças: Programa CPFL de valorização da diversidade. Campinas, CPFL, folheto.

_ (2002). Código de ética e de conduta empresarial. Campinas, CPFL, setembro, folheto.

DUPONT (2002). "Integrare". São Paulo, Dupont. Site: www.dupont.com.br/public/port/compromisso/projeto/\#16 (seção Compromisso Social/ Projetos Sociais). (2002). Balanço social 2002. São Paulo, Printon Gráfica \& Editora. 
ESCÓSSIA, Fernanda da. "Só 5,8 milhōes têm curso superior no Brasil". Folha de S. Paulo, 3 de dezembro.

ESTEVES, Sérgio A. P. (1999). Diversidade nas organizaçôes, uma visão atualizada. Brasília, OIT/Mtb/CERT/Div. OIT.

EXAME. Guia de Boa Cidadania Corporativa. São Paulo: Editora Abril, dezembro de 2002.

FELISBERTO, Fernanda \& DRUMOND, Kátia (2003). “Camélias pela inclusão: mais oportunidades para a população negra”. Afirma: Revista Negra Online, 17 de novembro. Site: www.afirma.inf.br/camelias.htm

FISCHER, Rosa Maria (s/d). O desafio da colaboração. Práticas de responsabilidade social entre empresas e o terceiro setor. São Paulo.

FLEURY, Maria Tereza Leme (2000). "Gerenciando a diversidade cultural: experiências de empresas brasileiras". Revista de Administração de Empresas, vol. 40, no 3, julho/setembro, pp. 18-25.

FONSECA, Neide (s/d). "Brasil e as ações afirmativas: a nossa luta faz a lei". São Paulo, INSPIR.

FRANCO, Simon (2000). "Combata o preconceito: exclusão é atraso. Deve ser refutada coletiva e individualmente”. Exame, 28 de junho, p. 131.

FOLHA DE S. PAULO. (2003). "Desigualdades", 8 de maio.

FOLHA DES. PAULO/O ESTADO DE S. PAULO (2003). "Faculdade terá $45 \%$ de vagas para negros e promete mensalidades mais baixas", 14 de maio.

FUNDAÇÃO BANKBOSTON (2003). "Geração XXI”. Site: www.bankboston.com.br/fundacao/projãgeracao.asp, seção "Projetos".

GIFE - Grupo de Institutos, Fundaçōes, e Empresas (2002). "Discriminação racial é menor nas empresas que investem no social”. São Paulo: redeGIFE, 11 de novembro. Site: www.gife.org.br

(2002). "Diversidade. O investimento social precisa de mais incentivo". São Paulo, redeGIFE, 22 de julho. Site: www.gife.org.br

_ (2002). "GIFE promove oficinas sobre investimento social privado e diversidade de gênero e raça”. São Paulo, redeGIFE, 22 de julho. Site: www.gife.org.br

_ (2002). "Marta Suplicy fala sobre diversidade em Encontro do GIFE”. São Paulo, redeGIFE, 4 de março. Site: www.gife.org.br

GROTTERA (1996). Qualé o pente que te penteia?: o perfil do consumidor negro no Brasil. São Paulo, GROTTERA.

HARVARD BUSINESS REVIEW (2001). Harvard Business Review on managing diversity. Cambridge, MA, Harvard Business School Press.

HENRIQUES, Ricardo (2003). "Silêncio - o canto da desigualdade racial". Rio de Janeiro, IETS, 20 de novembro. Site: www.iets.org.br, seção Desigualdade e Pobreza/Ponto de Vista.

_ (2001). Desigualdade racial no Brasil: evolução das condiçôes de vida na década de 90. Brasília, IPEA, julho.

HERCULANO, Mônica. "Ações pela diversidade estão mais no conceito do que na Prática”. São Paulo, redeGIFE, 24 de novembro. Site: www.gife.org.br (2002). "Diversidade aumenta criatividade de equipes em empresas e organizações da sociedade civil”. São Paulo, redeGIFE, 22 de julho. Site: www.gife.org.br 


\section{Aaron Myers}

HERINGER, Rosana (2003). "The challenge of practice: affirmative action and diversity programs in Brazil and the U.S.”. Washington, DC, Woodrow Wilson Center, setembro.

(2003). "Promoção da igualdade racial no Brasil: 2002-2003". Tempo e Presença, Ano 25, no 330, julho/agosto. Suplemento Especial, pp. 1-12.

_ (2001). "Mapeamento de ações e discursos de combate às desigualdades raciais no Brasil". Estudos Afro-Asiáticos, Ano 23, no 2, julho/dezembro, pp. 291-334.

(1999). A cor da desigualdade. Desigualdades raciais no mercado de trabalho e ação afirmativa no Brasil. Rio de Janeiro, Aerographic.

IMPRENSA FORD (2002). "Programa de diversidade da Ford é citado como exemplo". São Paulo, Ford, março. Site: www.ford.com.br/institucional/noticiasã124.asp.

INSTITUTO ETHOS (2003). “Padaria Saint Germain é ‘Top 30” por valorizar funcionários e apoiar comunidade”. São Paulo, Instituto Ethos, 17 de abril. Site: www.ethos.org.br

e Ibope Opinião, em parceria com FGV-SP, Ipea, OIT, e Unifem (2003). Perfil social, racial e de gênero das 500 maiores empresas do Brasile suas açôes afirmativas. São Paulo, Instituto Ethos, dezembro.

(2002). "Fersol aposta na contratação de pessoas de grupos excluídos para crescer". São Paulo, Instituto Ethos, 20 de janeiro. Site: www.ethos.org.br, veja Banco de Práticas/Público Interno/Attitude, p. 1-3).

, Ipea, OIT, Unifem e FGV-EAESP (2002). Perfil social, racial e de gênero das diretorias das grandes empresas brasileiras. São Paulo, Instituto Ethos, janeiro (panfleto). (2002). "Valorização da diversidade faz parte da cultura da Dupont". São Paulo, Instituto Ethos, 16 de janeiro. Site: www.ethos.org.br, veja Banco de Práticas/Público Interno/Casos (pp. 2-26).

_ (2002). "Dupont investe na promoção de minorias". São Paulo, Instituto Ethos, 1 de novembro. Site: www.ethos.org.br

(2002). "BankBoston busca melhorar condições de competição dos jovens negros na sociedade". São Paulo, Instituto Ethos, 13 de março. Site: www.ethos.org.br (2001). "Mulher é questão de primeira importância na política da Fersol”. São Paulo, Instituto Ethos, 31 de julho. Site: www.ethos.org.br

_ (2001). "Analistas recomendam compra de ações de empresas socialmente responsáveis”. São Paulo, Instituto Ethos, 11 de julho. Site: www.ethos.org.br

_ (2000). "Ford do Brasil investe na diversidade e difunde trabalho comunitário". São Paulo, Instituto Ethos, 8 de novembro. Site: www.ethos.org.br

- (vários autores) (2000). Como as empresas podem (e devem) valorizar a diversidade. São Paulo, Instituto Ethos, setembro.

_ (2000). "Projeto Geração XXI". São Paulo: Instituto Ethos, 1 de setembro. Site: www.ethos.org.br, ver Banco de Práticas/Public Interest/Attitude, pp. 2-25).

INSPIR - Instituto Sindical Interamericano pela Igualdade Racial. Site: www.inspir.org.br

(2004). "Afinal, o que são açōes afirmativas?". Revista Inspir-Ação, dez/jan/fev. (2002). Igualdade: Viver sem preconceitos. São Paulo, Editora Raiz da Terra Ltda. (s/d). INSPIR: Instituto Sindical Interamericano pela Igualdade Racial (folheto bilíngüe). São Paulo, Brasil Editora. 
(1999). Mapa da população negra no mercado de trabalho no Brasil. São Paulo, Centro de Solidariedade AFL-CIO, outubro. Relatório completo (133 páginas) e versão popular (26 páginas).

INTEGRARE: Centro de Integração de Negócios. Site: www.integrare.org.br (2003). Welcome to Brasil. São Paulo, Integrare, novembro.

JORNAL DE PSICOLOGIA (1999). "Diversidade Mostra que o Preconceito é Improdutivo”. São Paulo, Ano 17, no 118, setembro/outubro, p. 15.

KLISKSBERG, B (1997). O desafio da exclusão. São Paulo, Ed. Fundap, p. 25.

KODAK (2002). "Kodak brasileira lança Fórum da Diversidade no Brasil”. São José dos Campos, Kodak, 22 de janeiro. Site: wwwbr.kodak.com/country/BR/pt/novidades/noticiasLocais/teforum.shtml.

LOYOLA, Leandro (2003). "Desafio da inclusão é superar dificuldades históricas". $V a$ lor Econômico, 26 de junho, p. F-1.

MINISTÉRIO DO TRABALHO E EMPREGO (2003). Núcleos de promoção da igualdade de oportunidade e de combate à discriminação no trabalho. Brasília, MTE, Assessoria Internacional.

_ _Ministério da Justiça/OIT (1996). Encontro tripartite sobre implementação de políticas voltadas à diversidade. São Paulo, OIT/MJ/MTE, outubro.

MONSANTO (2003). Perfil Monsanto do Brasil. São Paulo, Babenko/Activa Design, agosto.

__ (s/d) "Monsanto e a Comunidade". Site: www.monsanto.com.br/institucional/index.htm (seção Institucional).

MONTEIRO, Jorge Aparecido (2003). "Jorge Aparecido Monteiro defende o fortalecimento do empreendedorismo negro no Brasil”. São Paulo, Instituto Ethos, 11 de novembro. Site: www.ethos.org.br/sistemas/comunicacao/noticias/vnoticiasãimp.asp? destaque $=5359$.

_ (2003). "Empresários negros e desigualdades de oportunidades". Conexão Negra, Ano 1, n. 2, p. 12.

— (2001). O empresário negro. Histórias de vida e trajetória de sucesso em busca da afirmação social. Rio de Janeiro, OR Editorial.

_ (1989). "A questão racial e a administração de recursos humanos nas empresas brasileiras". Revista de Administração de Empresas, vol. 29, n. 1, pp. 53-59.

MONTEIRO, José Pinto \& BRILHANTE, Vandré (2002). Afro-ascendentes: uma proposta de ascensão para of futuro do Brasil. Rio de Janeiro, Instituto Xerox/CIEDS.

MYERS, Aaron (2002). The emergence of affirmative action in Brazil. Tese de mestrado, New York, Columbia University School of International \& Public Affairs (SIPA).

OBSERVATÓRIO SOCIAL (2003). “Com a palavra, os atores sociais”. Responsabilidade Social Empresarial. Florianópolis, BANGRAF, outubro, ano 2, n. 4, pp. 37-43. (2002). ABN Amro: Comportamento Sociale Trabalhista. Florianópolis: BANGRAF, novembro.

OIT/MTb (1998). Brasil, gênero e raça. Todos unidos pela igualdade de oportunidades. Discriminação: teoria e prática. Programa Nacional de Direitos Humanos. Brasília, OIT/MTb. 


\section{Aaron Myers}

OLIVEIRA, Lúcia Helena; PORCARO, Rosa Maria \& ARAÚJO, Tereza Cristina N. (1985). Lugar do negro na força do trabalho. Rio de Janeiro, IBGE.

OLIVEIRA, Maurício (2000). "Mercado de trabalho já valoriza as minorias". Gazeta Mercantil, 19, 20, e 21 de maio.

PACHECO, Edmundo Dantes (2002). "KBL diversity initiatives” (apresentação de PowerPoint, em inglês). São José dos Campos, Kodak (Documento interno).

PADILHA, Darcilene (2000). "A experiência da Levi Strauss no Brasil”. In M. A. da S. Bento (org.), Ação afirmativa e diversidade no trabalho: desafios e possibilidades. São Paulo, Casa do Psicólogo Pgs. 185 - 194.

PIZA, Edith (2000). "O teto de vidro ou o céu não é o limite". In M. A. da S. Bento (org.), Ação afirmativa e diversidade no trabalho: desafios e possibilidades. São Paulo, Casa do Psicólogo, pp. 99-122.

QUALIAFRO. Site: www.portalafro.com.br/qualiafro/qualiafro.htm.

ROSENBURG, Cynthia (2002). "Dow: com sotaque". Guia de boa cidadania corporativa. São Paulo, Editora Abril, dezembro, pp. 42-43.

SANTOS, Helio (2003). “Sustentabilidade e diversidade”. Apresentação no lançamento do Programa CPFL de Valorização da Diversidade. Campinas, SP, 18 de dezembro (documento interno de CPFL).

SANTOS, Helio (2003). Apresentação na oficina "Políticas de valorização da diversidade no trabalho: construindo uma agenda" no seminário "Desafios das Políticas Públicas de Promoção da Igualdade Racial”, 16 e 17 de dezembro. São Paulo, SESC Vila Mariana. Coordenação do Centro de Estudos das Relações de Trabalho e Desigualdades.

SCHARF, Regina (2001). "ONG vai certificar empresas de negros e de minorias". Gazeta Mercantil, 16 de agosto, p. A-8.

SILVA, Cidinha da (org.) (2003). Açôes afirmativas em educação: experiências brasileiras. São Paulo, Summus.

SILVA, Jorge da (2001). "Política de ação afirmativa para a população negra: educação, trabalho, e participação no poder". In A. Vogel (org.), Trabalhando com a diversidade no PLANFOR (Plano Nacional de Qualificação do Trabalhador): raçalcor, gênero, $e$ pessoas portadores de necessidades especiais. São Paulo, UNESP/OREAL/MTE/FAT/FLACSO.

SILVA, Márcia Regina de Lima (2001). Serviço de "branco", serviço de "preto”. Um estudo sobre "cor" e trabalho no Brasil urbano. Tese de doutorado em Sociologia, Rio de Janeiro, Universidade Federal do Rio de Janeiro/IFCS.

SILVA JR., Hédio (2000). "Ação afirmação na Constituição de 1988”. In M. A. da S. Bento (org.), Ação afirmativa e diversidade no trabalho: desafios e possibilidades. São Paulo, Casa do Psicólogo.

SIGOLLO, Walter. "Igualdade e diversidade no trabalho". In M. A. da S. Bento e M. Castelar, Inclusão no trabalho: desafios e perspectivas. São Paulo, Casa do Psicólogo, pp. 145-154.

SOMOGGI, Laura (1999). “Combinação produtiva: reunir num único ambiente pessoas de diferentes raças, religiôes, idades, e estilos de vida é uma estratégia eficiente. Essa é a opinião do BankBoston e de muito outras empresas”. Você S.A., Ano 2, n. 17 , novembro, pp. 112-115. 
SUCUPIRA, João (2001). "O balanço social das empresas". In M. A. da S. Bento e M. Castelar, Inclusão no trabalho: desafios e perspectivas. São Paulo, Casa do Psicólogo, pp. 137-141.

ROOSEVELT JR., Thomas R. \& WOODRUFF, Majorie I. (1999). Building a house for diversity: how a fable about a giraffe \& an elephant offers new strategies for today's workforce. New York, NY, AMACOM.

UPDATE: Revista mensal da Câmara Americana de Comércio de São Paulo (2003). "Para fazer negócios: Entidade que promove inclusão social por meio de laços empresariais reafirma necessidade de políticas específicas", Ano XIX, n. 398, outubro, pp. 48-49.

VALENTE, Edson (2002). “Contratação afirmativa”. Folha de S. Paulo, 3 de fevereiro, p. E4.

VASSALLO, Cláudia (2000). "Viva a Diferença!. Porque a diversidade do capital humano pode tornar as empresas mais criativas, competitivas e poderosas". Exame, 6 de setembro, pp. 153-164.

(1995). "Afro-brasileiros primeiro: As filiais americanas introduzem no Brasil a ação afirmativa. Ela garante oportunidades no trabalho para negros, mulheres....". Exame, n. 593, 27 de setembro, pp. 74-76.

WESTIN, Felipe Vasquez (2001). "Experiências empresariais no Brasil. O conceito de diversidade da Monsanto”. In M. A. S. Bento e M. Castelar, Inclusão no trabalho: desafios e perspectivas. São Paulo, Casa do Psicólogo, pp. 163-168.

XAVIER, Paulo Roberto (Presidente Associação Paulista de Administração de Recursos Humanos) (2003). Apresentação na oficina "Políticas de valorização da diversidade no trabalho: construindo uma agenda" no seminário "Desafios das Políticas Públicas de Promoção da Igualdade Racial”, 16 e 17 de dezembro, São Paulo, SESC Vila Mariana. Coordenação do Centro de Estudos das Relações de Trabalho e Desigualdades.

XEROX do Brasil (2003). "Afro-Ascendentes”. Rio de Janeiro.

ZACHARY, G. Pascal e VASSALLO, Cláudia (2000). "Mestiçagem Global”. Exame, n. 722, 6 de setembro, pp. 166-171. 